\title{
Relationship between different normal serum bilirubin concentrations and diabetic nephropathy in patients with type 2 diabetes mellitus
}

\author{
Prof.Ali Mahmoud Kassem, ; Prof.Eman Ahmed Sabet; \\ Dr.Mohamed Eid Ahmed; Ahmed Shokry Ahmed, M.B.B.CH \\ Internal Medicine Department, Faculty of Medicine,Sohag University.
} \begin{abstract}
Background: One of the major complications of type 2 diabetes is diabetic nephropathy (DN). Nephropathy develops in $\sim 20-40 \%$ of patients with diabetes and is the single leading cause of end-stage renal disease (ESRD) around the world.(1) Oxidative stress has been considered to be an important pathogenic factor in the development of diabetic vascular complications, including nephropathy. Bilirubin(BIL) has been recognized as an endogenous antioxidant.

Objective: The objective of this study is to detect the relationship between serum bilirubin concentrations and diabetic nephropathy in patients with type 2 diabetes mellitus.

PATIENTS \& METHODS:The study included 92 patient with type 2 diabetes mellitus who visit Sohag University Hospital ,All patients in this study were subjected to full history taking, complete physical examination, and laboratory investigations including urine analysis, albumin creatinine ratio, renal and liver function tests. Patients with T2DM were recruited and bilirubin concentrations were compared between patients with or without diabetic nephropathy. DN was diagnosed according to KDOQI Clinical Practice Guidelines and Clinical Practice Recommendations for Diabetes and Chronic Kidney Disease ${ }^{\text {(7) }}$

Patients were classified according to stage of nephropathy ${ }^{(8):}$

1 -stage $1 \quad$------ albumin creatinine ratio less than $30 \mathrm{mg} / \mathrm{g}$ creatinin.

2-stage $2 \quad$------ morphologic lesions without signs of clinical disease.

3 -stage 3 ------ albumin creatinine ratio more than 30 , less than $300 \mathrm{mg} / \mathrm{g}$

creatinin.

4-stage $4 \quad$------- albumin creatinine ratio more than $300 \mathrm{mg} / \mathrm{g}$ creatinin.

5- stage $5 \quad$------- end stage renal disease.
\end{abstract}

Results: Multiple stepwise regression analysis was used to examine the relationship between bilirubin concentrations (within normal range) and albumin creatinin ratio.

\section{Conclusions}

Serum bilirubin concentration correlated negatively with stage of diabetic nephropathy, which suggests that bilirubin has a potential role for protection of diabetic nephropathy.

\section{Introduction}

Nephropathy develops in $\sim 20-40 \%$ of patients with diabetes and is the single leading cause of end-stage renal disease (ESRD) around the world.(1)
In recent years, oxidative stress has been considered to be an important pathogenic factor in the development of diabetic vascular complications, including nephropathy.

Bilirubin(BIL) has been recognized as an endogenous antioxidant for many years, as its formation is mediated by the expressed hemeoxygenase (HO), the rate-limiting enzyme involved in heme catabolism.(2) 
HO participates in heme breakdown to generate biliverdin(BVD), free ferrous iron and carbon monooxide. Subsequently, BVD is rapidly converted to BIL by BVD reductase. Recently, increasing evidence has suggested that $\mathrm{HO}$ and its reaction product BIL may serve as important endogenous agents with cytoprotective activity against oxidative stress injury.(3-5)

Information on the associations of serum bilirubin concentration with renal function and proteinuria is limited and controversial. studies found that total serum bilirubin was positively associated with eGFR and negatively associated with albuminuria in a hospital-based sample of 633 Japanese type 2 diabetic patients(6), indicating that bilirubin has a potential renoprotective effect .

Other study reviewed the medical records of 1363 adults aged 18 years or older who were seen at Kosin University Gospel Hospital (Busan, Republic of Korea) in the five-year period from January 2005 to December 2009. This study demonstrated that serum total bilirubin concentration was negatively correlated with 24-hour urine protein and was positively correlated with eGFR in Korean nondiabetic and diabetic adults.

\section{PATIENTS \& METHODS:}

-Place of the study: Sohag University Hospital

-Type of the study: Cross sectional clinical based study.

-Study period: 6 months

- Patients:

Inclusion criteria:

All type 2 diabetic patients.

All patients with serum bilirubin concentrations within normal range.

All stage of diabetic nephropathy except stage 5.

Exclusion criteria:
Type 1 diabetic patients.

Patients with urinary tract infection.

Patients on regular dialysis.

Pregnancy.

Patients with any conditions that can affect bilirubin concentrations as any liver disease, blood diseases, malignancy.

Methods :

All patients in this study were subjected to full history taking, complete physical examination, and laboratory investigations including urine analysis, albumin creatinine ratio, renal and liver function tests. Patients with T2DM were recruited and bilirubin concentrations were compared between patients with or without diabetic nephropathy. DN was diagnosed according to KDOQI Clinical Practice Guidelines and Clinical Practice Recommendations for Diabetes and Chronic Kidney Disease .(7) Patients were classified according to stage of nephropathy $(\mathbf{8})$ :

1-stage 1 ------ albumin creatinine ratio less than $30 \mathrm{mg} / \mathrm{g}$ creatinin.

2-stage $2 \quad$------ morphologic lesions without signs of clinical disease.

3-stage 3 ------ albumin creatinine ratio more than 30 , less than $300 \mathrm{mg} / \mathrm{g}$ creatinin.

4-stage 4 ------- albumin creatinine ratio more than $300 \mathrm{mg} / \mathrm{g}$ creatinin.

5- stage 5 ------ end stage renal disease.

Statistical analysis:

Multiple stepwise regression analysis was used to examine the relationship between bilirubin concentrations and albumin creatinin ratio. Data was analyzed using STATA intercooled version 14.2. Quantitative data was represented as mean, standard deviation, median and range. Data was analyzed using student t-test to 
compare means of two. When the data was not normally distributed MannWhitney test was used to compare two groups. Test for trend was used to compare quantitative data in ordered group. Qualitative data was presented as number and percentage and compared using either Chi square test or fisher exact test. Pearson's correlation analysis was used find the correlation between different variables. Univariate and multivariate regression analysis was used to find factors affecting albumin creatinine ration. Graphs were produced by using Excel or STATA program.

\section{Results:}

Initially the study included 163 patients with type 2 diabetes mellitus who visit Sohag University Hospital in a period of 6 months from 1/12/2017 to 1/5/ 2018 . 71 patients were excluded from the study and 92 patients finally included and were analyzed.The mean age of the study group was 53 years (SD: 7.7 years). Range was 38-72 years. Regarding sex, 43 patients were males $(47.25 \%)$ and 48 patients were females $(52.7 \%)$. (Table 1$)$.

(Table 1): Age and gender distribution of studied population

\begin{tabular}{|l|l|}
\hline Variable & Summary statistics \\
\hline Age/year & \\
Mean \pm SD & $53.24 \pm 7.76$ \\
Median (range) & $51(38-72)$ \\
\hline Gender & \\
Females & $43(47.25 \%)$ \\
Males & $48(52.75 \%)$ \\
\hline
\end{tabular}

Regarding medical history of the studied population, as regard smoking, $49.45 \%$ never smoke (45 patients) while $20.88 \%$ of our study group had past history of smoking (19 patients). And 27 patients of our study group are current smoker (29.7\%) (Table 2). Regarding the hypertention, 47 patients were not hyprtensive in our study group (51.65\%) while 44 patients were hypertensive $(48.53 \%)$ (Table 2). Regarding the duration of diabetes, the mean 9.87 with (SD: 6.35), range was (1- 31) years (table 2). As regard type of diabetic treatment, $(51.65 \%)$ of the patients were on oral treatment (47) patients, while 44 patients $(48.35 \%)$ were on insulin treatment (table 2).

(Table 2):.Medical history of studied population

\begin{tabular}{|l|l|}
\hline Variable & Summary statistics \\
\hline Smoking & \\
Never & $45(49.45 \%)$ \\
Past & $19(20.88 \%)$ \\
Current & $27(29.67 \%)$ \\
\hline Hypertension & $47(51.65 \%)$ \\
No & $44(48.35 \%)$ \\
Yes & \\
\hline Duration of diabetes & $9.87 \pm 6.35$ \\
Mean \pm SD & $9(1-31)$ \\
Median (range) & \\
\hline Type of diabetic treatment & $47(51.65 \%)$ \\
Oral & $44(48.35 \%)$ \\
Insulin & \\
\hline
\end{tabular}

Regarding the stage of diabetic nephropathy, 35 patients of the study group were stage 1 and $2(38.46 \%) .36$ patients were stage $3(39.56 \%)$, and 20 patients were stage $4(21.98 \%)$. (Table 3) 
SOHAG MEDICAL JOURNAL Relationship between different normal serum bilirubin concentrations

(Table 3) Stage of diabetic nephropathy of studied population

\begin{tabular}{|c|c|}
\hline Kidney disease stage & Summary statistics \\
\hline Stage 1 \& 2 & $35(38.46 \%)$ \\
Stage 3 & $36(39.56 \%)$ \\
Stage 4 & $20(21.98 \%)$ \\
\hline
\end{tabular}

Regarding the laboratory investigations of the study population, the mean of total bilirubin 0.76 (SD: 0.27; range: 0.2-1.2) (Table 4). The mean of serum creatinine was 1.03 (SD: 0.34; range: 0.3-2.1), (table 4). Regarding Albumin creatinine ratio, the mean was 283.21 (SD: 460.69; range: 1-2102). (Table 4)

(Table 4) Lab investigations of studied population

\begin{tabular}{|c|c|}
\hline Variable & Summary statistics \\
\hline Total bilirubin & \\
Mean \pm SD & $0.76 \pm 0.27$ \\
Median (range) & $0.8(0.2-1.2)$ \\
\hline Serum creatinine & $1.03 \pm 0.34$ \\
Mean \pm SD & $1(0.3-2.1)$ \\
Median (range) & \\
\hline Albumin creatinine ratio & $283.21 \pm 460.69$ \\
Mean \pm SD & $52(1-2102)$ \\
Median (range) & . \\
\hline
\end{tabular}

Multiple analysis were done to find any relationship between total bilirubin and different variables of the study (gender, smoking, hypertension, type of diabetic treatment and stage of diabetic nephropathy). (Table 5)

(Table5) Relationship of total bilirubin and different variables

\begin{tabular}{|c|c|c|c|}
\hline Variable & Number & Mean \pm SD, median (range) & P value \\
\hline Gender & 43 & $0.72 \pm 0.23,0.7(0.3-1.2)$ & 0.30 \\
Females & 48 & $0.79 \pm 3.1,0.85(0.2-1.2)$ & 0.31 \\
Males & 45 & $0.73 \pm 0.24,0.8(0.2-1.2)$ & \\
\hline Smoking & 19 & $0.77 \pm 0.34,0.8(0.3-1.2)$ & 0.21 \\
Never & 27 & $0.8 \pm 0.26,(0.8-0.2)$ & \\
Past & 47 & $0.79 \pm 0.25,0.8(0.3-1.2)$ & 0.53 \\
Current & 44 & $0.72 \pm 0.29,0.8(0.2-1.2)$ & \\
\hline Hypertension & 47 & $0.77 \pm 0.25,0.8(0.2-1.2)$ & $<0.0001$ \\
No & 44 & $0.74 \pm 0.29,0.8(0.2-1.2)$ & \\
\hline Yes & 35 & $0.96 \pm 0.20,1(0.3-1.2)$ & \\
\hline Oral & 36 & $0.73 \pm 0.17,0.7(0.4-1.1)$ & \\
Insulin & 20 & $0.45 \pm 0.19,0.4(0.2-1.0)$ & \\
\hline Stage 1 \& 2 of diabetic treatment & & & \\
\hline Stage 3 & & & \\
Stage 4 & & & \\
\hline
\end{tabular}

Our results show that there was no relationship between total bilirubin and different variables (gender, smoking, hypertension and type of diabetic treatment). While there was obvious relationship between total bilirubin and stage of diabetic nephropathy ( $p$ value $<0.0001)$

Multiple analysis were done to find relationship of serum creatinin and different variables of the study (gender, smoking, hypertension, type of diabetic treatment and stage of diabetic nephropathy). (Table 6) 
SOHAG MEDICAL JOURNAL Relationship between different normal serum bilirubin concentrations

(Table6) Relationship of serum creatinine and different variables

\begin{tabular}{|c|c|c|c|}
\hline Variable & Number & Mean \pm SD, median (range) & $\mathrm{P}$ value \\
\hline $\begin{array}{c}\text { Gender } \\
\text { Females } \\
\text { Males }\end{array}$ & $\begin{array}{l}43 \\
48\end{array}$ & $\begin{array}{l}0.98 \pm 0.31,1.0(0.4-1.9) \\
1.08 \pm 0.37,1.0(0.3-2.1)\end{array}$ & 0.18 \\
\hline $\begin{array}{l}\text { Smoking } \\
\text { Never } \\
\text { Past } \\
\text { Current }\end{array}$ & $\begin{array}{l}45 \\
19 \\
27\end{array}$ & $\begin{array}{l}0.98 \pm 0.32,0.9(0.4-1.9) \\
1.08 \pm 0.29,1.0(0.7-1.9) \\
1.07 \pm 0.42,1.0(0.3-2.1)\end{array}$ & 0.56 \\
\hline $\begin{array}{c}\text { Hypertension } \\
\text { No } \\
\text { Yes }\end{array}$ & $\begin{array}{l}47 \\
44\end{array}$ & $\begin{array}{c}0.96 \pm 0.30,0.9(0.4-1.9) \\
1.1 \pm 0.37,1.0(0.3-2.1)\end{array}$ & 0.06 \\
\hline $\begin{array}{c}\text { Type of diabetic treatment } \\
\text { Oral } \\
\text { Insulin }\end{array}$ & $\begin{array}{l}47 \\
44\end{array}$ & $\begin{array}{l}0.99 \pm 0.31,1.0(0.3-1.9) \\
1.06 \pm 0.38,1.0(0.4-2.1)\end{array}$ & 0.38 \\
\hline $\begin{array}{c}\text { Kidney disease stage } \\
\text { Stage } 1 \& 2 \\
\text { Stage } 3 \\
\text { Stage } 4\end{array}$ & $\begin{array}{l}35 \\
36 \\
20\end{array}$ & $\begin{array}{l}0.84 \pm 0.28,0.8(0.3-1.8) \\
1.03 \pm 0.26,1.0(0.4-1.9) \\
1.36 \pm 0.35,1.3(0.8-2.1)\end{array}$ & $<0.0001$ \\
\hline
\end{tabular}

Our results show that there was no relationship between serum creatinin and different variables (gender, smoking, hypertention and type of diabetic treatment). While there was obvious relationship between it and stage of diabetic nephropathy ( $p$ value $<0.0001)$.

Multiple analyses were done to find relationship of albumin creatinine ratio and different variables of the study (gender, smoking, and hypertension, type of diabetic treatment and stage of diabetic nephropathy). (Table7)

(Table7) Relationship of albumin creatinine ratio and different variables

\begin{tabular}{|c|c|c|c|}
\hline Variable & Number & Mean \pm SD, median (range) & $\mathrm{P}$ value \\
\hline $\begin{array}{l}\text { Gender } \\
\text { Females } \\
\text { Males }\end{array}$ & $\begin{array}{l}43 \\
48\end{array}$ & $\begin{array}{c}230.51 \pm 301.22,111(2-1302) \\
330.42 \pm 566.15,42(1-2102)\end{array}$ & 0.38 \\
\hline $\begin{array}{l}\text { Smoking } \\
\text { Never } \\
\text { Past } \\
\text { Current }\end{array}$ & $\begin{array}{l}45 \\
19 \\
27\end{array}$ & $\begin{array}{c}267.31 \pm 407.70,111(2-2102) \\
294.89 \pm 442.53,92(3-1313) \\
301.48 \pm 562.97,40(1-2100)\end{array}$ & 0.37 \\
\hline $\begin{array}{c}\text { Hypertension } \\
\text { No } \\
\text { Yes }\end{array}$ & $\begin{array}{l}47 \\
44\end{array}$ & $\begin{array}{c}180.21 \pm 279.47,49(1-1302) \\
393.23 \pm 580.25,94.5(2-2102)\end{array}$ & 0.22 \\
\hline $\begin{array}{c}\text { Type of diabetic treatment } \\
\text { Oral } \\
\text { Insulin }\end{array}$ & $\begin{array}{l}47 \\
44\end{array}$ & $\begin{array}{c}235.47 \pm 406.29,50(2-2102) \\
334.20 \pm 512.34,66.5(1-2100)\end{array}$ & 0.66 \\
\hline $\begin{array}{c}\text { Diabetic nephropathy stage } \\
\text { Stage } 1 \& 2 \\
\text { Stage } 3 \\
\text { Stage } 4\end{array}$ & $\begin{array}{l}35 \\
36 \\
20\end{array}$ & $\begin{array}{c}18.37 \pm 10.14,23(1-30) \\
144.22 \pm 95.74,125.5(31-321) \\
966.85 \pm 535.16,856(361-2102)\end{array}$ & $<0.0001$ \\
\hline
\end{tabular}

Our results show that there was no relationship between serum creatinin and different variables (gender, smoking, hypertension and type of diabetic treatment). While there was obvious relationship between it and stage of diabetic nephropathy ( $\mathrm{p}$ value $<0.0001)$.

There was correlation between total bilirubin and duration of diabetes ( $\mathrm{p}$ value 0.01 ), serum creatinine ( $\mathrm{p}$ value .001) and albumin creatinie ratio ( $\mathrm{p}$ value <0.0001) (Table 8) 
SOHAG MEDICAL JOURNAL Relationship between different normal serum bilirubin concentrations

(Table 8) Correlation between total bilirubin and different quantities variable

\begin{tabular}{|c|c|c|}
\hline Variable & Correlation co-efficient & P value \\
\hline Age/year & -0.21 & 0.04 \\
\hline Duration of diabetes & -0.26 & 0.01 \\
\hline Serum creatinine & -0.35 & 0.001 \\
\hline Albumin creatinine ratio & -0.72 & $<0.0001$ \\
\hline
\end{tabular}

There was correlation between serum creatitne and duration of diabetes ( $\mathrm{p}$ value0.01), serum bilirubin ( $\mathrm{p}$ value .001) and albumin creatinie ratio ( $\mathrm{p}$ value <0.0001) (Table 9).

(Table 9) Correlation between serum creatinine and different quantities variable

\begin{tabular}{|c|c|c|}
\hline Variable & Correlation co-efficient & P value \\
\hline Age/year & 0.27 & 0.01 \\
\hline Duration of diabetes & 0.29 & 0.01 \\
\hline Total bilirubin & -0.36 & 0.001 \\
\hline Albumin creatinine ratio & 0.54 & $<0.0001$ \\
\hline
\end{tabular}

There was correlation between Albumin creatinine ratio and duration of diabetes ( $\mathrm{p}$ value 0.001 ), serum bilirubin ( $\mathrm{p}$ value $<.0001$ ) and serum creatinine ( $\mathrm{p}$ value $<0.0001$ )

(Table 10) Correlation between Albumin creatinine ratio and different quantities variable

\begin{tabular}{|c|c|c|}
\hline Variable & Correlation co-efficient & P value \\
\hline Age/year & 0.21 & 0.04 \\
\hline Duration of diabetes & 0.34 & 0.001 \\
\hline Total bilirubin & -0.72 & $<0.0001$ \\
\hline Serum creatinine & 0.54 & $<0.0001$ \\
\hline
\end{tabular}

Our results also showed that there was a significant negative relationship between total billirubin and albumin creatinin ratio.

(Table 11) Univariate regression analysis of factors affecting albumin creatinine ratio

\begin{tabular}{|c|c|c|}
\hline Variable & Regression coefficient (95\% CI) & P value \\
\hline Age/years & $12.44(0.22-24.67)$ & 0.046 \\
\hline Male gender & $99.91(-92.23: 292.04)$ & 0.30 \\
\hline Past smoker vs. past & $27.58(-225.58: 280.75)$ & 0.83 \\
Past smoker vs. current & $34.17(-191.08: 259.43)$ & 0.76 \\
\hline Hypertension & $213.01(25.20-400.83)$ & 0.03 \\
\hline Duration of diabetes & $25.20(10.88-39.53)$ & 0.001 \\
\hline Insulin Vs. oral & $98.74(-93.24: 290.71)$ & 0.31 \\
\hline Total bilirubin & $-1220.32(-1469.86:-970.77)$ & $<0.0001$ \\
\hline
\end{tabular}

(Table 12) Multivariate regression analysis of factors affecting albumin creatinine ratio

\begin{tabular}{|c|c|c|}
\hline Variable & Regression coefficient (95\% CI) & P value \\
\hline Age/years & $-2.57(-13.02: 7.89)$ & 0.63 \\
\hline Male gender & $229.72(-88.33: 467.76)$ & 0.36 \\
\hline Past smoker vs. past & $-142.49(-406.64: 121.66)$ & 0.29 \\
Past smoker vs. current & $-70.97(-315.15: 173.21)$ & 0.57 \\
\hline Hypertension & $63.94(-75.40: 203.28)$ & 0.36 \\
\hline Duration of diabetes & $13.21(0.15: 26.29)$ & 0.048 \\
\hline Insulin Vs. oral & $21.48(-112.84: 155.79)$ & 0.75 \\
\hline Total bilirubin & $-1166.80(-1420:-912.88)$ & $<0.0001$ \\
\hline
\end{tabular}

At the end our result we found that albumin creatinine ratio can be affected by both duration of diabetes and total bilirubin (Table 11.12and13) 
(Table 13) Final factors affecting albumin creatinine ratio

\begin{tabular}{|l|l|l|}
\hline Variable & Regression coefficient $(95 \%$ CI $)$ & P value \\
\hline Duration of diabetes & $11.49(1.01: 21.96)$ & 0.03 \\
\hline Total bilirubin & $-1183.75(-1430.82:-936.68)$ & $<0.0001$ \\
\hline
\end{tabular}

\section{Discussion}

Our study assessed the relationship between different normal serum bilirubin concentrations and diabetic nephropathy in patients with type 2 diabetes mellitus.

Initially the study included 163 patients with type 2 diabetes mellitus who visit Sohag University Hospital in a period of 6 months from $1 / 12 / 2017$ to $1 / 5 / 2018$. 71 patients were excluded from the study and 92 patients finally included and were analyzed.

The mean of the age of the study group was 53 years, 43 patients were males and 48 patients were females and this was not significant statistically.

Our study demonstrated that serum total bilirubin concentration was negatively correlated to albumin creatinine ratio which ensures the role of bilirubin as antioxidant giving renoprotective effect.

As regard relationship between total bilirubin and different variables of the study (gender, smoking, hypertension, type of diabetic treatment and stage of diabetic nephropathy. Our results show that there was no relationship between total bilirubin and different variables (gender, smoking, hypertension and type of diabetic treatment). While there was obvious relationship between total bilirubin and stage of diabetic nephropathy ( $\mathrm{p}$ value $<0.0001$ ).

In agreement with our results, Fukui et $\mathrm{al}^{(9)}$ That previous study found that total serum bilirubin was positively associated with eGFR and negatively associated with albuminuria in a hospital-based sample of 633 Japanese type 2 diabetic patients (mean age: $64.4 \pm 11.5$ years; $52 \%$ male).
Another study Ho Sik Shin, Yeon Soon Jung, and Hark Rim ${ }^{(\mathbf{1 0})}$, inverse correlation was found between total serum bilirubin concentration and 24hour urine albumin in all type 2 diabetes milletus

In contrast to our study, the results of Targher et $\mathrm{al}^{(\mathbf{1 1})}$ in their observational large hospital-based sample of 2678 adult outpatients (mean age: $55 \pm 18$ years; $43 \%$ male), including 210 diabetic patients. In that study, they found that serum total bilirubin was inversely associated with eGFR in both non-diabetic $(\mathrm{r}=-0.17 ; \mathrm{p}<0.0001)$ and diabetic patients $(\mathrm{r}=-0.14 ; \mathrm{p}<$ $0.05)$ ). However, no information was available on albuminuria,

As regard stage of diabetic nephropathy ( $\mathrm{p}$ value<0.0001) correlate negatively with the serum total bilirubin at our study. In agreement with our results Ho Sik Shin, Yeon Soon Jung, and Hark Rim ,Serum bilirubin concentrations were lower in patients with macroalbuminuria than in patients with normoalbuminuria $(\mathrm{P}<0.0001)$ or microalbuminuria $(\mathrm{P}=0.0012)$, and serum bilirubin concentrations were lower in patients with microalbuminuria than in patients with normoalbuminuria $(\mathrm{P}=0.0418)$.

During our study, multiple analyses were done to find relationship of albumin creatinine ratio and different variables of the study (gender, smoking, and hypertension, type of diabetic treatment and stage of diabetic nephropathy). Our results show that there was no relationship between total bilirubin and different variables (gender, smoking, hypertension and type of diabetic treatment). While there 
was obvious relationship between total bilirubin and stage of diabetic nephropathy, and our result also found that albumin creatinine ratio can be affected by both duration of diabetes and total bilirubin. But Fukui et al ${ }^{(\mathbf{9})}$ showed multiple regression analysis demonstrated that age, duration of diabetes, hemoglobin A1C (HbA1c), systolic blood pressure, serum triglyceride concentration, and serum bilirubin concentration were independent determinants of $\log$ (urinary albumin excretion)

In agreement to our study Fukui et al $^{(9)}$ showed that serum bilirubin concentrations did not differ between patients treated with and without insulin $(P=0.3863$

In contrast to our study, Fukui et al ${ }^{(9)}$ showed that Serum bilirubin concentrations were lower in patients with current smokers than in patients with past smokers $(P=0.0294)$. But, our study show no relationship between serum bilirubin concentrations and smoking $(P=0.31)$

Our results found that $(48.53 \%)$ of the patients were hypertensive and diabetic and (Ho Sik Shin, Yeon Soon Jung (10) found that Diabetes and hypertension were present in $44.9 \%$ of patients

Recommendation: We recommend to perform usual testing for total billirubin in patients with type 2 diabetes mellitus which can be indicator for stage of nephroathy .

\section{References:}

1. Ritz E, Rychlik I, LocatelliF,etal.Endstage renal failure in type 2 diabetes: amedical catastrophe of worldwide dimensions.Am J Kidney Dis1999; 34: $795-808$.

2. Stocker R, Yamamoto $\mathrm{Y}, \mathrm{McD}$ onagh $\mathrm{AF}$, et al.: Bilirubin is an antioxidant of possible physiological importance.
235:1043-1046, 198.

3.Stocker R: Induction of haemoxygenase as a defence against oxidative stress. Free Radic Res Commun9:101-112, 1990.

4.Abraham NG, Kappas A: Hemeoxygenase and the cardiovascular-renal system. Free RadicBiol Med39:1-25, 2005.

5.Morita T: Hemeoxygenase and atherosclerosis.

ArteriosclerThrombVasc Biol25:17861795, 2005.

6. Fukui M, Tanaka M, Shiraishi E, Harusato I, Hosoda H, Asano M, Hasegawa G, Nakamura N: Relationship between serum bilirubin and albuminuria in patients with type 2 diabetes. Kidney Int. 2008, 74: 11971201

7. KDOQI. KDOQI Clinical Practice Guidelines and Clinical Practice Recommendations for Diabetes and Chronic Kidney Disease. Am J Kidney Dis. 2007;49.

8. Giacco F, Brownlee M (2010) Oxidative stress and diabetic complications. Circ Res 107: 1058107.

9. Fukui M, Tanaka M, Shiraishi E, Harusato I, Hosoda H, Asano M, Hasegawa G, Nakamura N. Relationship between serum bilirubin and albuminuria in patients with type 2 diabetes. Kidney Int. 2008;74:11971201. doi:

10.Ho Sik Shin,1 Yeon Soon Jung, 1 and Hark Rim凶1 Relationship of serum bilirubin concentration to kidney function and 24-hour urine protein in Korean adults.

11. Targher G, Zoppini G, Cesare Guidi G, Lippi G. Relationship between serum bilirubin and kidney function in non-diabetic and diabetic individuals. Kidney Int. 2009;75:863 